\title{
Controle e susceptibilidade de capim-braquiária e capim-ruziziensis ao glyphosate e fluazifop-p-butil
}

Silveira, R.R. ${ }^{\text {; }}$ Santos, M.V. ${ }^{\text {; }}$ Ferreira, E.A. ' ; Braz, T.G.S. ${ }^{2}$; Santos, J.B. ' ; Andrade, J.C.A. ' ; Costa, J.P.R. '; Silva, A.M.S. ${ }^{\text { e }}$ Silva, L.D.1@

'Universidade Federal dos Vales do Jequitinhonha e Mucuri. Diamantina. Minas Gerais Brasil.

${ }^{2}$ Universidade Federal de Minas Gerais. Montes Claros. Minas Gerais. Brasil.

\section{PALAVRAS CHAVE ADICIONAIS}

Brachiaria decumbens.

Brachiaria ruziziensis.

Controle químico.

Pastagem.

Tolerância.

\section{RESUMO}

\begin{abstract}
Este estudo teve como objetivo avaliar o controle e susceptibilidade de capim-braquiária e capim-ruziziensis em crescimento inicial submetidos a diferentes doses dos herbicidas glyphosate e fluazifop-p-butil. Os tratamentos foram arranjados no esquema fatorial $2 \times 6$, com cinco repetições, sendo duas gramíneas: Brachiaria decumbens cv. Basilisk (capim-braquiária) e B. ruziziensis (capim-ruziziensis), e seis doses dos herbicidas: 0,$00 ; 0,25 ; 0,50 ; 1,00 ; 1,5$ e 2,00 vezes a dose comercial indicada pelos fabricantes. Aos 7, 15, 21 e 30 dias após aplicação dos herbicidas (DAA) foram avaliadas visualmente a intoxicação em capim-braquiária e capim-ruziziensis. O glyphosate causou intoxicação de 100\% em plantas de capimbraquiária e capim-ruziziensis, mesmo na menor dose (90 g ha-1), podendo ser utilizado com eficiência para o controle dessas espécies no início de desenvolvimento. Foi observado que as plantas submetidas ao fluazifop-p-butil apresentaram rebrota apenas nas doses aplicadas até $100 \mathrm{~g}$ ha-1 para capim-braquiária e $50 \mathrm{~g}$ ha-1 para o capim-ruziziensis. Esses resultados confirmam a eficiência dessa molécula herbicida no controle dessas duas espécies a partir das doses de $200 \mathrm{~g}$ ha-1 e $100 \mathrm{~g}$ ha-1 para capim-braquiária e capim-ruziziensis, respectivamente.
\end{abstract}

\section{Control and susceptibility of signalgrass and ruzigrass to glyphosate and fluazifop-p-butil}

\section{SUMMARY}

\section{ADDITIONAL KEYWORDS}

Brachiaria decumbens.

Brachiaria ruziziensis.

Chemical control.

Pasture.

Tolerance.

\section{INFORMATION}

Cronología del artículo.

Recibido/Received: 15.05 .2018

Aceptado/Accepted: 21.03.2019

On-line: 15.07.2019

Correspondencia a los autores/Contact e-mail:

leandro.silva@ufv.br

\section{INTRODUÇÃO}

Com a crescente utilização de sistemas de integração entre lavoura, pecuária e, ou, floresta (ILP ou ILPF) em regiões tropicais de baixa fertilidade do solo, como no Brasil, as espécies do gênero Brachiaria (Syn. Urochloa) vêm se destacando devido as características desejáveis para utilização nesses consórcios, principalmente quando da adoção da semeadura direta. As espécies do gênero Brachiaria apresentam em geral elevada produtividade, facilidade de dessecação e boa ciclagem de nutrientes devido a adequada relação $\mathrm{C} / \mathrm{N}$ e lignina/N, o que possibilita maior tempo de permanência da palhada no solo (Franchini et al. 2015). 
Além disso, as espécies com maior facilidade de dessecação proporcionam uma redução do uso de herbicidas para semeadura da cultura agrícola e reduz a competição com a mesma, favorecendo a produção de grãos (Ceccon \& Concenço 2014).

A B. decumbens (capim-braquiária) é a espécie mais difundida entre os pecuaristas pela adaptação a solos ácidos e de baixa fertilidade natural, facilidade de manejo e multiplicação por sementes, além da vantagem competitiva com plantas daninhas, resultando em bom desempenho animal (Valle et al. 2010). Concomitantemente, outra espécie que vem crescendo sua utilização é a B. ruziziensis (capim-ruziziensis). O capimruziziensis vem sendo muito utilizado para formação de palhada em plantio direto devido a boa cobertura do solo e supressão de plantas daninhas (Borges et al. 2014). Além disso, nos sistemas de cultivo integrado o capim-ruziziensis apresenta vantagem em relação ao capim-braquiária por não apresentar dormência das sementes, o que facilita o controle devido à germinação homogênea do banco de sementes contido no solo, diferente do capim-braquiária que apresenta germinação irregular, dificultando seu controle e podendo resultar em competição com a cultura agrícola em consórcio (Carmona 1992). Devido a essas características do capim-braquiária, a substituição dessa espécie por outra forrageira gramínea não é uma pratica fácil, tanto em sistemas consorciados quanto para renovação de pastos em monocultivo, podendo ser considerada nesses casos como planta daninha. Além disso, há inexistência de herbicidas graminicidas que sejam seletivos para espécies forrageiras e que apresentam controle de plantas daninhas monocotiledonares.

Existem trabalhos que reportam o uso de herbicidas no controle de plantas gramíneas forrageiras de diferentes gêneros (Santos et al. 2008, 2012), no entanto, há poucos estudos na literatura com o uso de herbicidas avaliando a seletividade de espécies forrageiras do mesmo gênero taxonômico, como Brachiaria. Desse modo, fica evidente a necessidade do conhecimento sobre a susceptibilidade diferencial do capim-braquiária e capim-ruziziensis aos herbicidas para idealizar estratégias de renovação de pastagens.

Dentre os herbicidas utilizados para controle de gramíneas destaca-se o glyphosate e o fluazifop-pbutil. O glyphosate é um herbicida não seletivo, de amplo espectro, controlando plantas monocotiledôneas e dicotiledôneas através da inibição da enzima 5-enol piruvil shikimato-3-fosfato sintase (Steinrücken \& Amrhein 1980). Já o fluazifop-p-butil, é um herbicida seletivo que controla monocotiledôneas inibindo a enzima acetil-CoA carboxilase (Rendina \& Felts 1988). Os estudos de diferentes doses desses herbicidas podem promover uma reposta de susceptibilidade diferenciada nas gramíneas possibilitando o controle da espécie desejada.

Assim, este trabalho foi proposto com o objetivo de avaliar o controle e susceptibilidade de capim-braquiária e capim-ruziziensis em crescimento inicial submetidos a diferentes doses dos herbicidas glyphosate e fluazifop-p-butil.

\section{MATERIAL E MÉTODOS}

Os ensaios foram conduzidos entre os meses de fevereiro a agosto de 2013 , em casa de vegetação, $18^{\circ}$ $14^{\prime}$ de latitude sul, $43^{\circ} 36^{\prime}$ de longitude oeste e 1.288 metros de altitude, Minas Gerais. O clima da região é tropical de altitude, classificado por Köppen-Geiger como Cwb. O solo foi coletado em uma área de pastagem, em Couto de Magalhães de Minas - MG, $18^{\circ} 4^{\prime}$ de latitude sul, $43^{\circ} 28^{\prime}$ de longitude oeste e 733 metros de altitude. $\mathrm{O}$ solo utilizado foi classificado como Latossolo Vermelho-Amarelo, apresentando as seguintes características químicas: $\mathrm{pH}\left(\mathrm{H}_{2} \mathrm{O}\right)=5,12 ; \mathrm{P}=1,02 \mathrm{mg}$ $\mathrm{dm}^{-3}$ (Mehlich); $\mathrm{K}=25,3 \mathrm{mg} \mathrm{dm}^{-3} ; \mathrm{Ca}^{+2}=0,40$ cmolc $\mathrm{dm}^{-3} ; \mathrm{Mg}^{+2}=0,20 \mathrm{cmolc} \mathrm{dm}^{-3} ; \mathrm{Al}+3=0,76 \mathrm{cmolc} \mathrm{dm}^{-3}$; soma de bases $=0,66 \mathrm{cmolc} \mathrm{dm}^{-3} ; \mathrm{H}+\mathrm{Al}=5,20 \mathrm{cmolc}$ $\mathrm{dm}^{-3}$; matéria orgânica $=0,70 \mathrm{dag} \mathrm{kg}^{-1}$; areia $=47 \%$; e argila $=53 \%$. Após a análise, a cada $100 \mathrm{~kg}$ de solo foram adicionados $120 \mathrm{~g}$ de calcário dolomítico, $500 \mathrm{~g}$ de superfosfato simples, $30 \mathrm{~g}$ de sulfato de amônio e $20 \mathrm{~g}$ cloreto de potássio (Cantarutti et al. 2007).

O delineamento experimental utilizado foi inteiramente casualizado com cinco repetições. Os tratamentos foram arranjados no esquema fatorial $2 \times 6$, sendo duas gramíneas: Brachiaria decumbens cv. Basilisk (capim-braquiária) e B. ruziziensis (capim-ruziziensis) (Syn. Urochloa decumbens e Urochloa ruziziensis) e seis doses dos herbicidas: 0,$00 ; 0,25 ; 0,50 ; 1,00 ; 1,5$ e 2,00 vezes a dose comercial indicada pelos fabricantes. Foram realizados dois experimentos simultaneamente, em um ensaio foi utilizado o glyphosate e no outro o fluazifop-p-butil. As dosagens aplicadas dos herbicidas foram: 0, 90, 180, 360, 540 e 720 g e.a. ha ${ }^{-1}$ de glyphosate e 0, 50, 100, 200, 300 e $400 \mathrm{~g}$ i.a. ha $^{-1}$ de fluazifop-p-butil.

Cada unidade experimental foi constituída por um vaso contendo $7 \mathrm{dm}^{3}$ de solo peneirado. $\mathrm{O}$ capim-braquiária e o capim-ruziziensis foram semeados em bandejas na profundidade de um $\mathrm{cm}$, sendo transplantados 20 dias após a semeadura. Em cada vaso foram mantidas duas plantas de capim-braquiária intercaladas com duas plantas de capim-ruziziensis. As demais espécies de plantas que ocorreram nos vasos foram eliminadas manualmente. A irrigação foi realizada diariamente e a cada 14 dias foram efetuadas adubações em cobertura com 2,5 g por vaso da formulação $\mathrm{N}-\mathrm{P}_{2} \mathrm{O}_{5}-\mathrm{K}_{2} \mathrm{O}(20-5-20)$ previamente diluída em água.

Foram aplicados os herbicidas aos 30 dias após o transplantio das mudas para os vasos. A aplicação foi realizada com auxílio de um pulverizador costal, munido de um bico de jato plano (XR 11002), à pressão constante de $210 \mathrm{kPa}$ e um volume de calda equivalente a 200 L ha $^{-1}$. No momento da aplicação dos herbicidas as plantas estavam em estádio inicial de desenvolvimento, contendo de três a quatro perfilhos formados e média de 0,30 a 0,35 $\mathrm{m}$ de altura, simulando condições de plantas em área de pastagem em estabelecimento.

A fitotoxicidade foi avaliada visualmente aos 7, 15, 21 e 30 dias após a aplicação dos herbicidas (DAA), utilizando-se uma escala de 0 a $100 \%$, sendo 0 a ausência de intoxicação e 100\% a morte da planta. Esse procedimento foi realizado por dois avaliadores "as cegas" (EWRC 1964). 
Aos 30 DAA ambas as espécies foram cortadas ao nível do solo. As plantas cortadas de cada espécie foram separadas por fração verde e fração morta para determinação da massa seca senescente e total, sendo a massa total a somatória das frações verde e morta. As amostras totais de cada espécie por vaso foram acondicionadas em sacos de papel Kraft e colocadas em estufa de ventilação forçada a $55^{\circ} \mathrm{C}$, por 72 horas até peso constante, e posteriormente pesadas. Após o corte, os vasos foram irrigados diariamente e adubados quinzenalmente, para avaliação da capacidade de rebrota das duas gramíneas aos 60 dias após o corte (DAC), através da determinação do número de perfilhos totais e massa seca senescente e total. Nessa data, as plantas de ambas as espécies foram colhidas ao nível do solo, quantificado o número de perfilhos vivos e separado o material senescente das frações vivas, sendo posteriormente submetidos à secagem em estufa, semelhantemente ao descrito para 30 DAA.

Os resultados foram submetidos à análise de variância adotando-se 5\% como nível crítico para o erro do tipo I. Para avaliação de efeitos significativos de interação entre gramíneas, doses e épocas de avaliação foram realizadas análises de regressão. Para a escolha dos modelos foi considerado o ajuste do modelo em relação ao padrão de resposta da planta, o coeficiente de determinação e a significância do modelo e dos parâmetros. Os dados de massa total de forragem, massa senescente e número de perfilhos foram comparados por meio do teste Duncan. Todas as análises foram realizadas utilizando-se o programa estatístico do SAS (Statistic Analysis System).

\section{RESULTADOS E DISCUSSÃO}

\section{GlyphOSATE}

Aos 7 DAA foi observado maior intoxicação do capim-ruziziensis em comparação ao capim-braquiária (Figura 1). Esses resultados corroboram com a afirmação de Brighenti et al. (2011a). Segundo esses autores

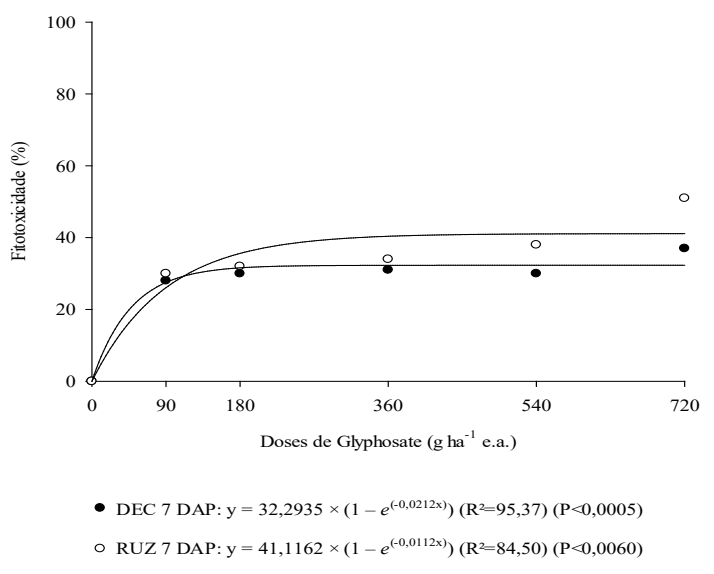

Figura 1. Efeito de dose de glyphosate na fitotoxicidade de Brachiaria decumbens (DEC) e B. ruziziensis (RUZ) a os 7 dias após aplicação (Efecto de la dosis de glifosato en la fitotoxicidad de Brachiaria Decumbens (DEC) y $B$. Ruziziensis (RUZ) a los 7 días posteriores a la aplicación). existe uma variabilidade entre as espécies de capim-braquiária e capim-ruziziensis, quanto à suscetibilidade ao herbicida glyphosate, sendo o capim-ruziziensis mais suscetível em comparação com o capim-braquiária. Além disso, o conhecimento dessa susceptibilidade diferenciada permite economia de 12 a $16 \%$ na dose do herbicida.

No presente trabalho observa-se também que, independentemente da dose aplicada, a fitotoxicidade de glyphosate aos 7 DAA foi baixa para ambas forrageiras estudadas, possivelmente, devido ao curto tempo para atividade completa da molécula do herbicida no metabolismo das plantas. Além disso, a molécula do herbicida necessita de um tempo mínimo para alcançar o interior da organela onde ocorre a ação do princípio ativo (Hess \& Falk 1990). Entretanto, a partir de 15 DAA a fitotoxicidade de glyphosate atingiu valores máximos (100\%) (Figura 2). Esses resultados indicam que, mesmo em doses mais baixas que a recomendada pelo fabricante, a morte das forrageiras capim-braquiária e capim-ruziziensis pode ser observada aos 15 DAA, em plantas submetidas a esse herbicida em fase inicial de desenvolvimento.

Moraes (2016) observaram que a dose de $90 \mathrm{~g}$ e.a. $\mathrm{ha}^{-1}$ de glyphosate reduziu drasticamente a massa fresca e seca das plantas de $B$. decumbens aos 30 dias após a semeadura, indicando assim que as plantas foram controladas em doses abaixo da recomendada. Vale ressaltar o efeito de doses mais baixas, como relatado por Nascentes et al. (2015), podem ocasionar o efeito de hormese. Esses autores relataram que o glyphosate na dose de 10,5 g e.a ha-1 aos 15 DAA, proporcionou incremento na produção de matéria seca de $31,8 \%$ em pasto estabelecido de Brachiaria brizantha cv. Marandu. Além disso, Silva et al. (2009) constataram que subdoses abaixo de $18 \mathrm{~g}$ e.a. ha-1 ocasionaram aumento em altura, e subdoses acima desse valor causaram reduções na altura de perfilhos em cana-de-açúcar. Outro ponto de relevância é a possibilidade de uma subdose levar a resistência, no entanto o herbicida não é mutagênico e como a resistência está codificada no genoma das plantas, as subdosagens podem influenciar no selecionamento, ou seja, na quantidade de plantas eliminadas (Christoffoleti et al., 1994).

Por outro lado, Brighenti et al. (2011a) observaram que o glyphosate teve eficiência de controle de $85 \%$ aos 25 DAA para capim-braquiária e capim-ruziziensis quando as plantas apresentavam entre 0,6 a $0,7 \mathrm{~m}$ de altura. Santos et al. (2008), utilizando o glyphosate no controle de plantas de $B$. brizantha cv. Marandu (capim-marandu) com altura de 0,4 m, observaram fitotoxicidade de $75 \%$ aos 15 DAA e $90 \%$ aos 30 DAA. No presente estudo a fitotoxicidade do herbicida, aos 15 DAA, foi maior em relação aos citados anteriormente, possivelmente devido a avaliação ter sido realizada em plantas menos desenvolvidas.

Nos estádios inicias de desenvolvimento os tecidos das plantas apresentam maior capacidade de transportar moléculas herbicidas e, consequentemente, menor capacidade de recuperação das injúrias causadas por esses. Com a formação da parede secundária, que é menos permeável e mais espessa que a parede primá- 

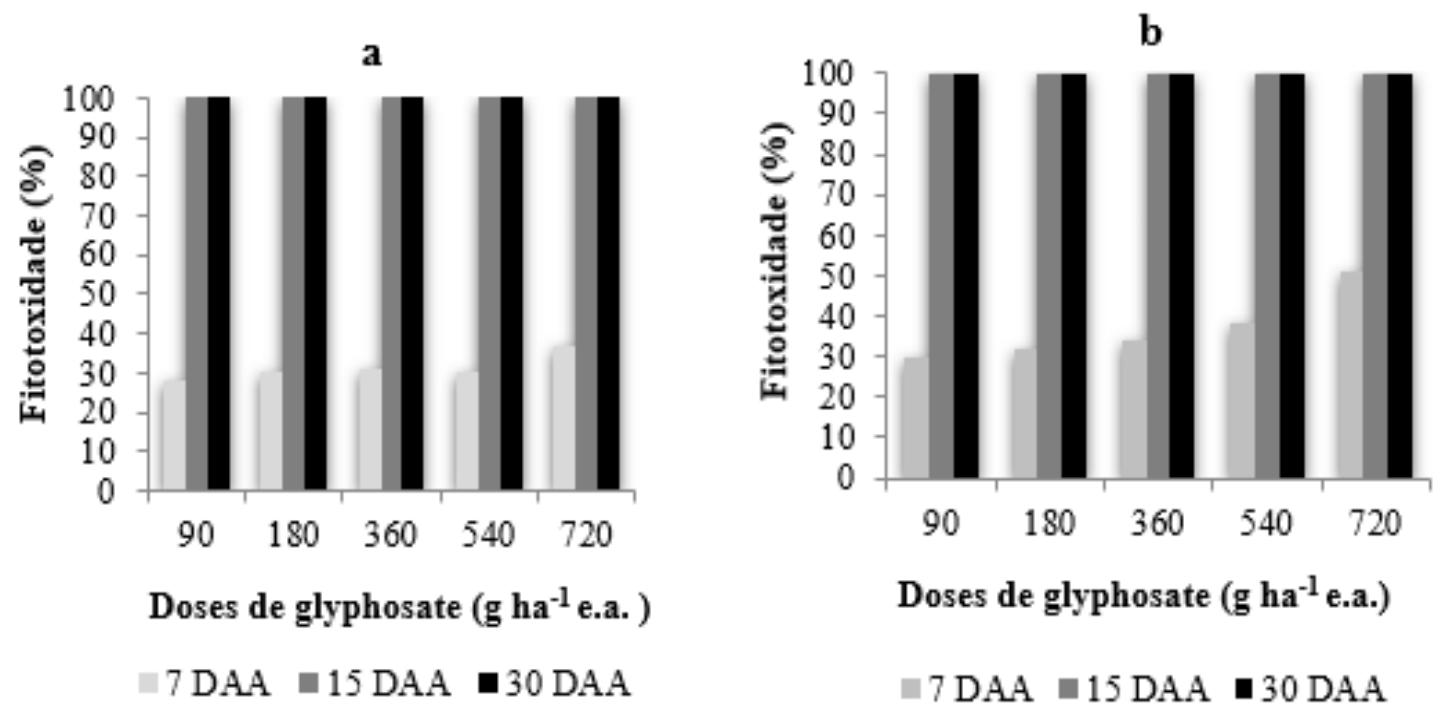

Figura 2. Efeito de dose de glyphosate na fitotoxicidade de Brachiaria decumbens (a) e B. ruziziensis (b), aos 7, 15 e 30 dias após aplicação (DAA) (Efecto de la dosis de glifosato en la fitotoxicidad de Brachiaria Decumbens (a) y B. Ruziziensis (b) a los 7, 15 y 30 días después de la aplicación (DAA).

ria, ocorre decréscimo na translocação de herbicidas em plantas mais velhas, necessitando aumentar a dose do herbicida para o controle das plantas (Marques et al. 2011).

Independentemente da dose de glyphosate e espécie forrageira, foram observados os mesmos valores de massa total e massa senescente onde foi aplicado o herbicida, em comparação ao tratamento sem herbicida
(Tabela I). Isso se deve ao fato de que aos 30 DAA foi observada total senescência das plantas forrageiras, confirmando a morte das mesmas a partir dos 15 DAA (Figura 2). Entretanto, esse resultado foi um pouco diferente do observado Costa et al. (2013). Esses autores observaram decréscimo na produção da massa de forragem de capim-marandu a partir das doses de $200 \mathrm{~g} \mathrm{ha}^{-1}$, com plantas em florescimento no pasto recém estabelecido. Esses resultados evidenciam que nos

Tabela I. Massa seca total e de material senescente (g planta ${ }^{-1}$ ) de Brachiaria decumbens e B. ruziziensis, aos 30 dias após a aplicação de doses de glyphosate e fluazifop-p-butil (Masa seca total y material senescente $(g$ plant-1) de Brachiaria Decumbens y $B$. Ruziziensis, a los 30 días siguientes a la aplicación de dosis de glifosato y FLUAZIFOP-p-butilo).

\begin{tabular}{|c|c|c|c|c|c|c|}
\hline \multirow{4}{*}{ Massa seca } & \multicolumn{6}{|c|}{ Equivalente da dose comerciala } \\
\hline & 0 & 0,25 & 0,5 & 1 & 1,5 & 2 \\
\hline & \multicolumn{6}{|c|}{ Glyphosate } \\
\hline & \multicolumn{6}{|c|}{ Brachiaria decumbens } \\
\hline Senescente & $0,34 \mathrm{~b}$ & 5,40 a & $5,32 \mathrm{a}$ & 5,26 a & 5,24 a & $5,02 \mathrm{a}$ \\
\hline \multirow[t]{2}{*}{ Total } & $3,08 \mathrm{~b}$ & 5,40 a & $5,32 \mathrm{a}$ & 5,26 a & $5,24 a$ & $5,02 \mathrm{a}$ \\
\hline & \multicolumn{6}{|c|}{ Brachiaria ruziziensis } \\
\hline Senescente & $0,38 \mathrm{~b}$ & 3,47 a & $3,36 \mathrm{a}$ & $3,26 a$ & $2,52 \mathrm{a}$ & $2,34 \mathrm{a}$ \\
\hline \multirow[t]{3}{*}{ Total } & $14,4 \mathrm{a}$ & $3,47 \mathrm{~b}$ & $3,36 \mathrm{~b}$ & $3,26 b$ & $2,52 b$ & $2,34 \mathrm{~b}$ \\
\hline & \multicolumn{6}{|c|}{ Fluazifop-p-butil } \\
\hline & \multicolumn{6}{|c|}{ Brachiaria decumbens } \\
\hline Senescente & $0,34 \mathrm{~b}$ & $0,38 \mathrm{~b}$ & $0,36 \mathrm{~b}$ & $0,54 \mathrm{~b}$ & $1,32 \mathrm{a}$ & $1,72 \mathrm{a}$ \\
\hline \multirow[t]{2}{*}{ Total } & 3,08 a & $2,52 \mathrm{~b}$ & $2,38 \mathrm{~b}$ & $2,26 \mathrm{~b}$ & $2,16 \mathrm{~b}$ & $2,14 \mathrm{~b}$ \\
\hline & \multicolumn{6}{|c|}{ Brachiaria ruziziensis } \\
\hline Senescente & $0,38 \mathrm{c}$ & $2,36 \mathrm{~b}$ & $7,34 \mathrm{a}$ & $7,30 \mathrm{a}$ & $7,22 \mathrm{a}$ & $7,18 \mathrm{a}$ \\
\hline Total & $14,4 \mathrm{a}$ & $8,94 a b$ & $9,16 a b$ & $8,94 a b$ & $7,79 \mathrm{~b}$ & $7,68 \mathrm{~b}$ \\
\hline
\end{tabular}




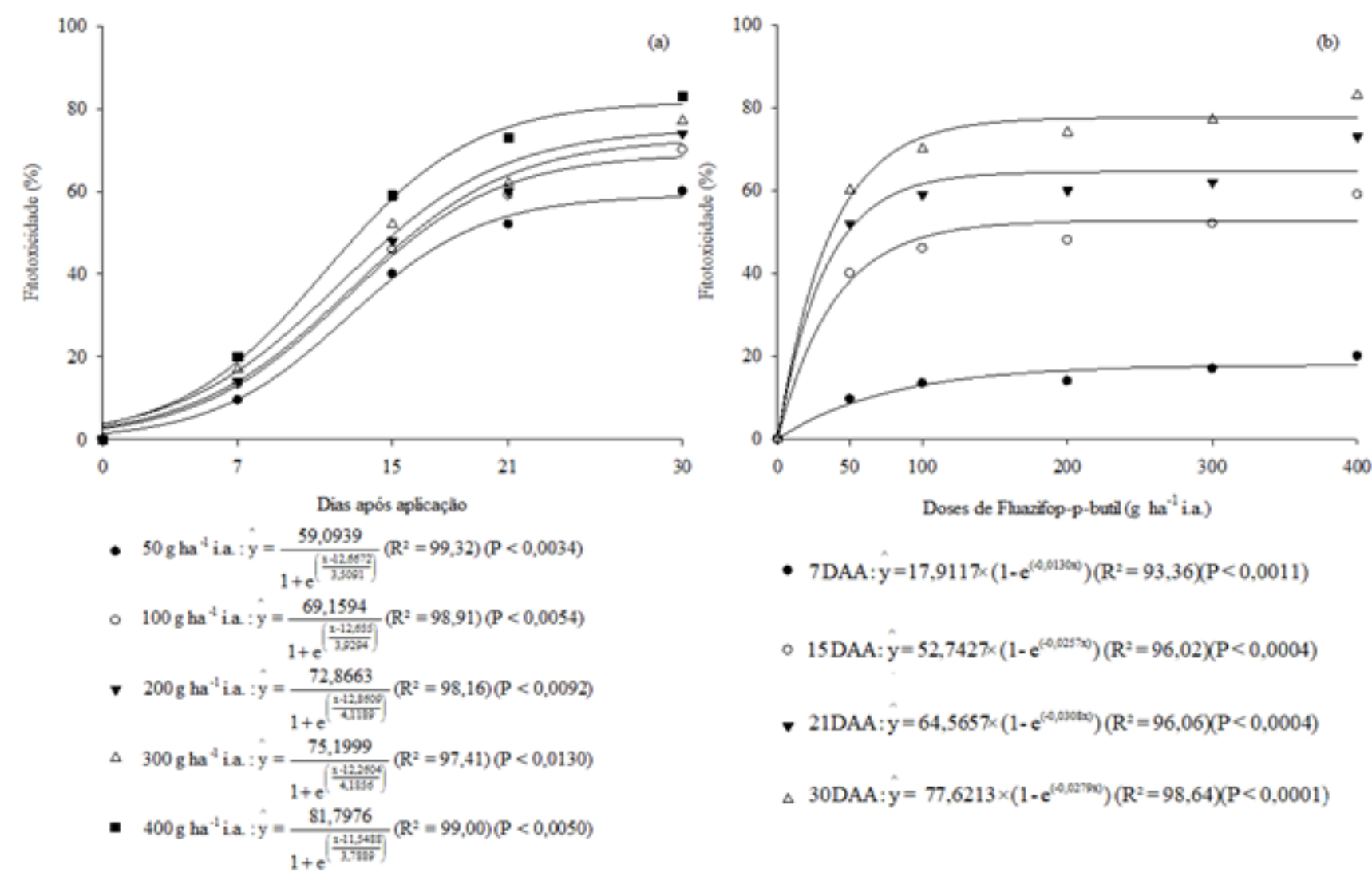

Figura 3. Efeito de dose de fluazifop-p-butil na fitotoxicidade de Brachiaria ruziziensis de acordo com os dias após a aplicação (a) e efeito de dias após a aplicação de acordo com as doses aplicadas (b) (Efecto de la dosis de FLUAZIFOP-p-butilo en la fitotoxicidad de Brachiaria ruziziensis según los días posteriores a la aplicación (a) y efecto de los días posteriores a la aplicación según las dosis aplicadas (b).

estádios iniciais de desenvolvimento dessas gramíneas do gênero Brachiaria é possível fazer o controle das plantas com uma menor dose de glyphosate em relação a recomendação do fabricante, porém em pastagens já estabelecidas não é possível diminuir a dose desse herbicida.
No presente estudo, aos 60 dias após o corte (DAC) das plantas, não foi observada rebrota para as plantas submetidas ao glyphosate, independentemente da espécie (Tabela II). Esses resultados confirmam a fitotoxicidade máxima do capim-braquiária e capim-ruziziensis em todas as doses

Tabela II. Número de perfilhos e massa seca $\left(\mathrm{g}_{\text {planta-1 }}{ }^{-1}\right)$ de Brachiaria decumbens e $B$. ruziziensis submetidas as doses de glyphosate e fluazifop-p-butil, aos 60 dias após o corte das plantas (Número de perfiles y materia seca (g plant-1) de Brachiaria Decumbens y B. Ruziziensis sometidos a dosis de glifosato y FLUAZIFOP-p-butilo, a los 60 días después del corte de la planta).

\begin{tabular}{|c|c|c|c|c|c|c|}
\hline \multirow{2}{*}{ Variáveis } & \multicolumn{6}{|c|}{ Equivalente da dose comerciala } \\
\hline & 0 & 0,25 & 0,5 & 1 & 1,5 & 2 \\
\hline & \multicolumn{6}{|c|}{ Glyphosate } \\
\hline & \multicolumn{6}{|c|}{ Brachiaria decumbens } \\
\hline Número de perfilhos & 0 & 0 & 0 & 0 & 0 & 0 \\
\hline \multirow[t]{2}{*}{ Massa seca total } & 0 & 0 & 0 & 0 & 0 & 0 \\
\hline & \multicolumn{6}{|c|}{ Brachiaria ruziziensis } \\
\hline Número de perfilhos & 0 & 0 & 0 & 0 & 0 & 0 \\
\hline \multirow[t]{3}{*}{ Massa seca total } & 0 & 0 & 0 & 0 & 0 & 0 \\
\hline & \multicolumn{6}{|c|}{ Fluazifop-p-butil } \\
\hline & \multicolumn{6}{|c|}{ Brachiaria decumbens } \\
\hline Número de perfilhos & $28 \mathrm{a}$ & $23 a$ & $18 \mathrm{~b}$ & $0 \mathrm{c}$ & $0 \mathrm{c}$ & $0 \mathrm{c}$ \\
\hline \multirow[t]{2}{*}{ Massa seca total } & $5,88 \mathrm{a}$ & $1,10 \mathrm{~b}$ & $0,94 \mathrm{~b}$ & $0 \mathrm{c}$ & $0 \mathrm{c}$ & $0 \mathrm{c}$ \\
\hline & \multicolumn{6}{|c|}{ Brachiaria ruziziensis } \\
\hline Número de perfilhos & $25 \mathrm{a}$ & $6 \mathrm{~b}$ & $0 \mathrm{c}$ & $0 \mathrm{c}$ & $0 \mathrm{c}$ & $0 \mathrm{c}$ \\
\hline Massa seca total & $6,02 \mathrm{a}$ & $1,80 \mathrm{~b}$ & $0 \mathrm{c}$ & $0 \mathrm{c}$ & $0 \mathrm{c}$ & $0 \mathrm{c}$ \\
\hline
\end{tabular}

${ }^{a}$ Medidas equivalentes da dose comercial: 0, 90, 180, 360, 540, $720 \mathrm{~g}$ e.a ha-1 de glyphosate; e 0, 50, 100, 200, 300 e $400 \mathrm{~g}$ i.a. ha-1 de fluazifop-p-butil. Médias seguidas pela mesma letra na linha não diferem entre si pelo teste Duncan a $5 \%$ de probabilidade. 
avaliadas, podendo inclusive a dose $90 \mathrm{~g} \mathrm{ha}^{-1}$ ser utilizada no controle dessas plantas em fase inicial de desenvolvimento. Realmente o modo de ação dessa molécula herbicida é prejudicial para o metabolismo de todas as plantas, pois interrompe a principal enzima envolvida na síntese de aminoácidos essenciais, a enzima 5-enol piruvil shikimato-3-fosfato sintase, que paralisa totalmente o crescimento, além disso, resulta no acúmulo de substâncias que aceleram a morte da planta (Steinrücken \& Amrhein 1980). Vale ressaltar a necessidade de novos estudos avaliando a intoxicação dessas forrageiras em estádios iniciais de desenvolvimento à doses ainda menores que $90 \mathrm{~g} \mathrm{ha}^{-1}$ de glyphosate.

\section{FLUAZIFOP-P-BUTIL}

Houve efeito significativo de dose na fitotoxicidade de ambas as gramíneas. A maior intoxicação foi observada com a maior dose de fluazifop-p-butil (400 $\mathrm{g} \mathrm{ha}^{-1}$ ) aos 30 DAA (Figura 3a). Para o capim-ruziziensis a dose comercial resultou em fitotoxicidade de $70 \%$, enquanto que com a maior dose resultou em fitotoxicidade superior a $80 \%$, mostrando também a suscetibilidade do capim-ruziziensis a molécula de fluazifop-p-butil. Para o Ministério da Agricultura, Pecuária e Abastecimento (MAPA) a dose recomendada do herbicida para ser considerado viável deve possuir em média um controle de $80 \%$ do crescimento da planta (MAPA 2011).
Para o efeito de dias após a aplicação do herbicida na fitotoxicidade de capim-ruziziensis, nota-se melhor ajuste dos dados ao modelo sigmoidal de regressão, sendo que aos 30 DAA foram observados níveis de controle por volta de $80 \%$ com a dose de $400 \mathrm{~g} \mathrm{ha}^{-1}$ (Figura $3 \mathbf{b}$ ). Esses resultados evidenciam que o herbicida fluazifop-p-butil pode ser utilizado no controle capimruziziensis, com $30 \mathrm{~cm}$ de altura, utilizando dose a partir de $400 \mathrm{~g} \mathrm{ha}^{-1}$, ou seja, não é possível utilizar uma dose menor que a recomendada pelo fabricante para controle dessa gramínea, mesmo em estádio inicial de desenvolvimento.

Houve aumento na intoxicação das plantas de capim-braquiária com o aumento das doses do fluazifopp-butil com o passar do tempo (Figura 4a). Aos 30 DAA foi observada fitotoxicidade próxima de $80 \%$ em plantas de capim-braquiária na dose de $400 \mathrm{~g} \mathrm{ha}^{-1}$ de fluazifop-p-butil (Figura 4b). Entretanto, doses inferiores a $300 \mathrm{~g} \mathrm{ha}^{-1}$ de fluazifop-p-butil resultaram em fitotoxicidade menor que $70 \%$ aos 30 DAA. Assim a partir desses resultados pode-se inferir que para o fluazifop-p-butil, mesmo para capim-braquiária em desenvolvimento inicial, não se pode reduzir a dosagem recomendada pelo fabricante.

Entretanto, em estudo realizado por Barroso et al. (2010) com objetivo de controlar o capim-braquiária em lavoura de soja, os autores reportam fitotoxicidade de
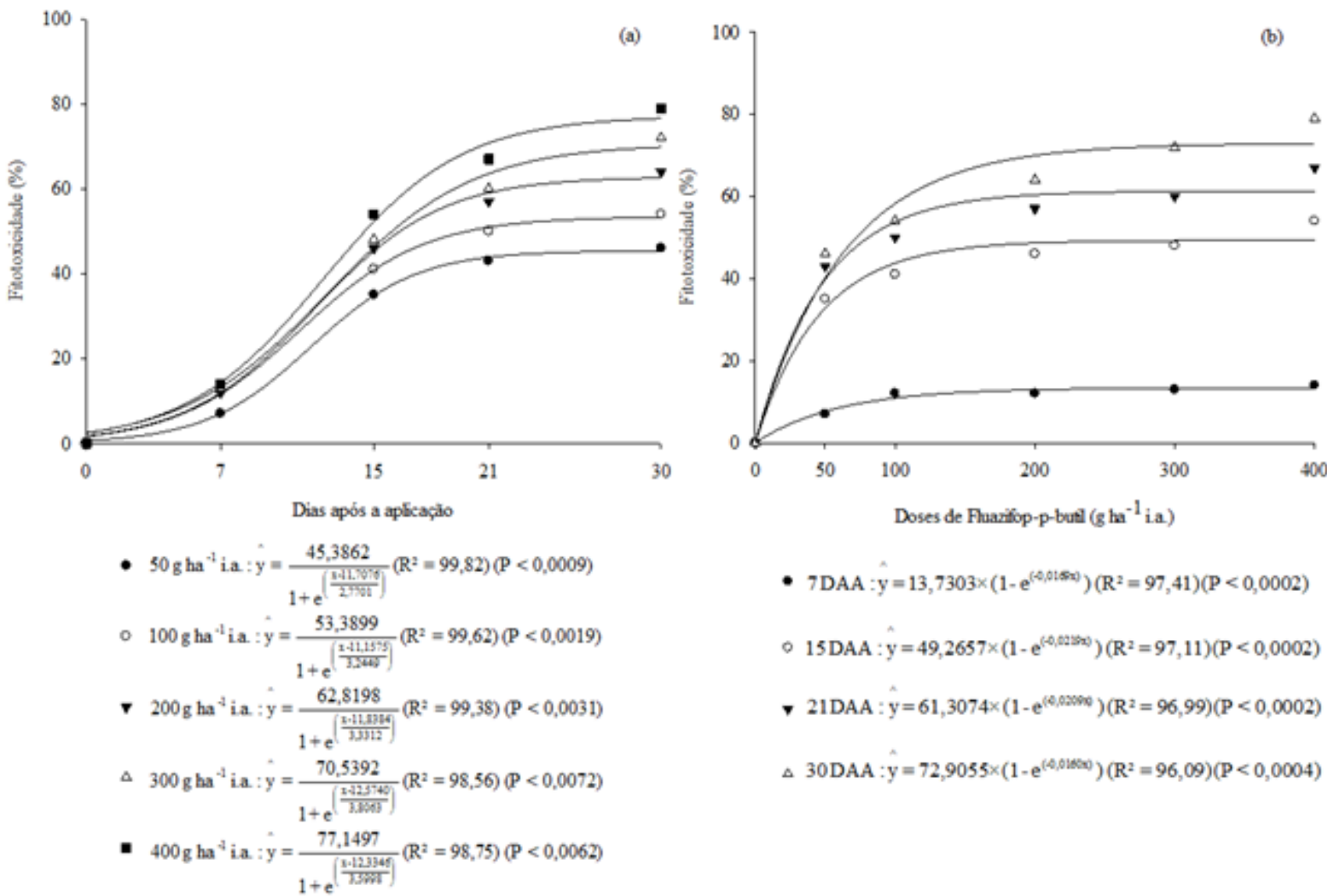

Figura 4. Efeito de dose de fluazifop-p-butil na fitotoxicidade de Brachiaria decumbens de acordo com os dias após a aplicação (a) e efeito de dias após a aplicação de acordo com as doses aplicadas (b) (Efecto de la dosis de FLUAZIFOP-p-butilo en la fitotoxicidad de Brachiaria Decumbens según los días posteriores a la aplicación (a) y efecto de los días posteriores a la aplicación según las dosis aplicadas (b)). 
$82 \%$ aos 29 DAA com utilização de $125 \mathrm{~g}$ ha $^{-1}$ de fluazifop-p-butil, em plantas com dois perfilhos. Além disso, Santos et al. (2012) observaram controle de B. brizantha de $84 \%$ em pastos de tifton 85 aos 21 DAA, utilizando $250 \mathrm{~g} \mathrm{ha}^{-1}$ de fluazifop-p-butil em plantas com $0,20 \mathrm{~m}$ de altura. Marques et al. (2011) avaliando diferentes herbicidas no controle de capim-braquiária aos 15, 23 e 48 dias após a emergência da planta, verificou intoxicação de 100, 91 e 9\%, respectivamente, com a dose de $150 \mathrm{~g} \mathrm{ha}^{-1}$ de fluazifop-p-butil. Esses autores afirmaram que a idade da planta é fundamental no controle em pós emergência, pois com o desenvolvimento da planta ocorre diminuição da capacidade de transportar moléculas, diminuindo o efeito dos herbicidas, além de aumentar a quantidade de reservas que proporcionam maior capacidade de recuperação. Os resultados desses últimos autores explicam a maior dose encontrada na atual pesquisa para controle de capim-braquiária e capim-ruziziensis com cerca de 0,30 a 0,35 m com uso do fluazifop-p-butil, em relação aos resultados reportados pelos demais autores citados acima.

Houve efeito da aplicação de fluazifop-p-butil na massa senescente de capim-braquiária a partir da dose de $300 \mathrm{~g} \mathrm{ha}^{-1}$ (Tabela I). Para a massa total, a menor dose já apresentou efeito em relação ao controle, porém não foi observado diferença entre a menor e a maior dose utilizada (doses de 50 a $400 \mathrm{~g} \mathrm{ha}^{-1}$ ) de fluazifop-pbutil. Em comparação com o tratamento controle houve redução de $31 \%$ na massa total de capim-braquiária com a aplicação de $400 \mathrm{~g} \mathrm{ha}^{-1}$ de fluazifop-p-butil. Possivelmente as menores doses tenham inibido parcial ou temporariamente a enzima ACCase, não ocasionando o aumento da senescência de tecidos das plantas. Santos et al. (2012) observaram, em capim-marandu com 0,20 $m$ de altura, decréscimo na massa total a partir da dose de $125 \mathrm{~g}$ ha $^{-1}$ de fluazifop-p-butil, aos 60 DAA.

A massa senescente aumentou com a aplicação de fluazifop-p-butil em capim-ruziziensis quando comparados ao controle. Os maiores valores de massa senescente foram observados para as doses maiores que $100 \mathrm{~g} \mathrm{ha}^{-1}$ de fluazifop-p-butil (Tabela I). Já na massa total de capim-ruziziensis não houve diferença entre as doses de 0 até $200 \mathrm{~g} \mathrm{ha}^{-1}$ e entre as doses de 50 até 400 gha $^{-1}$ de fluazifop-p-butil. Os menores valores de massa total para o capim-ruziziensis foram observados nas doses de 300 e $400 \mathrm{~g} \mathrm{ha}^{-1}$, apresentando redução de 46\% da massa total em comparação ao tratamento controle.

Silva et al. (2004) observaram reduções na massa total de capim-marandu a partir da dose $18 \mathrm{~g} \mathrm{ha}^{-1} \mathrm{de}$ fluazifop-p-butil, doses essas pequenas em relação ao presente estudo, porém suficientes para diminuir a produção de massa seca do capim-marandu aos 25 dias após a emergência da planta. Já Brighenti et al. (2011b) em estudos com capim-ruziziensis com dois perfilhos e média de $17,5 \mathrm{~cm}$ de altura submetidas as doses de 12,5 e 25,0 g i.a. ha ${ }^{-1}$ de fluzifop-p-butil não observaram efeito negativo na massa total de forragem, entretanto, concluíram que doses reduzidas desse herbicida podem ser utilizadas como reguladores de crescimento do capim-ruziziensis. Provavelmente, esse resultado se deve ao efeito do fluazifop-p-butil na redução do crescimento das plantas por meio da redução do perfilhamento. Um dos fatores que podem explicar a redução do perfilhamento é a inibição da ACCase, que resulta em disfunção da membrana celular paralisando o desenvolvimento, pois essa enzima é responsável pela reação inicial da síntese de lipídeos e, consequentemente, polarização das membranas celulares (Rendina \& Felts 1988).

Foi observado que as plantas submetidas ao fluazifop-p-butil apresentaram rebrota apenas nas doses aplicadas até $100 \mathrm{~g} \mathrm{ha}^{-1}$ para capim-braquiária e $50 \mathrm{~g}$ ha $^{-1}$ para o capim-ruziziensis (Tabela II). No entanto, esses novos perfilhos foram afetados pelo resíduo dos herbicidas, pois a massa total foi reduzida em comparação com a parcela sem aplicação do herbicida. De acordo com o fabricante o período de carência do herbicida pode variar de 28 a 60 dias e o período de persistência no solo em torno de 7 a 15 dias (WSSA, 1994). Esses resultados confirmam os níveis de intoxicações observado aos 30 DAA, e a eficiência dessa molécula herbicida no controle dessas duas espécies a partir das doses de $200 \mathrm{~g}_{\text {ha-1 }}$ e $100 \mathrm{~g} \mathrm{ha}^{-1}$ para capim-braquiária e capim-ruziziensis, respectivamente. Logo, é possível fazer o controle de capim-ruziziensis em pastagens de capim-braquiária utilizando-se metade da dose de fluazifop-p-butil recomendada pelo fabricante. Por outro lado, a utilização do capim-ruziziensis em detrimento ao capim-braquiária no sistema de semeadura direta possibilita economia de $50 \%$ no uso do herbicida. Entretanto não é possível o controle de capimbraquiária em pastos de capim-ruziziensis utilizando fluazifop-p-butil, devido a maior susceptibilidade da ruziziensis ao herbicida.

\section{CONCLUSÃO}

O capim-ruzizensis apresenta maior suscetibilidade ao fluazifop-p-butil e ao glyphosate que o capimbraquiária. A utilização de doses a partir de $90 \mathrm{~g} \mathrm{ha}^{-1} \mathrm{de}$ glyphosate permite o controle efetivo do crescimento inicial de ambas as forrageiras. Para o controle efetivo do capim-braquiária pode-se utilizar $200 \mathrm{~g} \mathrm{ha}^{-1} \mathrm{de}$ fluazifop-p-butil, e para o capim-ruziziensis a dose pode ser de $100 \mathrm{~g} \mathrm{ha}^{-1}$.

\section{AGRADECIMENTOS}

ACAPES, CNPq e FAPEMIG pelo suporte financeiro.

\section{BIBLIOGRAFIA}

Barroso, ALL, Dan, HA, Procópio, SO, Toledo, REB, Sandaniel, CR, Braz, GBP \& Cruvinel, KL 2010, 'Eficácia de herbicidas inibidores da ACCase no controle de gramíneas em lavouras de soja', Planta Daninha, vol. 28, no. 1, pp. 149-157.

Borges, WLB, Freitas, RS, Mateus, GP, SÁ, ME \& Alves, MC 2014, 'Supressão de plantas daninhas utilizando plantas de cobertura do solo', Planta Daninha, vol. 32, no. 4, pp. 755-763.

Brighenti, AM, Rocha, WSD, Souza Sobrinho, F, Castro, C, Martins, CE \& Muller, MD 2011 b, 'Application of reduced rates of accase-inhibiting herbicides to sun flower intercropped with Brachiaria ruziziensis', Helia, vol. 34, no. 54, pp. 39-48.

Brighenti, AM, Souza Sobrinho, F, Rocha, WSD, Martins, CE, Demartini, D, \& Costa, TR 2011 la, 'Suscetibilidade diferencial de espécies de 
braquiária ao herbicida glifosato', Pesquisa Agropecuária Brasileira, vol. 46, no. 10, pp. 1241-1246.

Cantarutti, RB, Barros, NF \& Martinez, HEP 2007, 'Avaliação da fertilidade do solo e recomendação de fertilizantes', in RF Novais (ed.), Fertilidade do solo, Sociedade Brasileira da Ciência do Solo, Viçosa, MG, Brasil, pp. 769-850.

Carmona, R 1992, 'Problemática e manejo de bancos de sementes de invasoras em solos agrícolas', Planta Daninha, vol. 10, no. 1/2, pp. 5-16

Ceccon, G \& Concenço, G 2014, 'Mass yield and burndown of perennial forages for crop-livestock integration', Planta Daninha, vol. 32, no. 2, pp. 319-326.

Christoffoleti, PJ, Victoria Filho, R \& Da Silva, CB 1994 'Resistência de plantas daninhas aos herbicidas', Planta Daninha, vol. 12, no. 1, pp. 13-20.

Costa, NV, Peres, EJL, Ritter, L Silva, PV \& Fey, E 2013, 'Avaliação do glyphosate e paraquat no manejo da Brachiaria ruziziensis', Revista Brasileira de Herbicidas, vol. 12, no. 1, pp.31-38.

European Weed Research Council (EWRC) 1964, 'Report of the 3nd and 4th meetings of EWRC: Committee of Methods in Weed Research', Weed Research, vol. 4, no. 1, pp.88.

Franchini, JC, Balbinot Junior, AA, Debiasi, H \& Conte, O 2015, 'Desempenho da soja em consequência de manejo de pastagem, época de dessecação e adubação nitrogenada', Pesquisa Agropecuária Brasileira, vol. 50, no. 12, pp.1131-1138.

Hess, FD \& Falk, RH 1990, 'Herbicide deposition on leaf surfaces', Weed Science, vol. 38, no. 3, pp. 280-288.

Marques, RP, Rodella, RA \& Martins, D 2011 , 'Controle químico em pósemergência de espécies de Brachiaria em três estádios vegetativos', Arquivos do Instituto Biológico, vol. 78, no. 3, pp.409-416.

Ministério da Agricultura Pecuária e Abastecimento - MAPA n.d. AGROFIT Sistemas de Agrotóxicos Fitossanitários, acesso em 25 agosto de 2016, <http://extranet.agricultura.gov.br/agrofit_cons/ principal_agrofit_cons>

Moraes, CP 2016, 'Controle e hormesis de glyphosate em Brachiaria decumbens'. Dissertação de mestrado, Faculdade de Ciências Agronômicas da Universidade do Estado de São Paulo, Botucatu, 62p.
Nascentes, RF, Fagan, EB, Soares, LH, Oliveira, CB \& Brunelli, MC 2015, 'Hormesis de Glyphosate em Brachiaria brizanta cv. Marandu'. Revista do Centro Universitário de Patos de Minas, vol. 6, pp. 55-64.

Rendina, AR \& Felts, JM 1988, 'Cyclohexanedione herbicides are selective and potent inhibitors of acetyl-CoA carboxylase from grasses', Plant Physiology, vol. 86, no. 4, pp. 983-986.

Santos, MV, Ferreira, FA, Freitas, FCL, Fonseca, DM, Carvalho, AJ \& Braz, TGS 2012, 'Brachiaria brizantha control by using fluazifop-pbutil on Tifton 85 pasture formation', Revista Brasileira de Zootecnia, vol. 41, no. 2, pp. 281-285.

Santos, MV, Ferreira, FA, Freitas, FCL, Ikeda, AK, Oliveira, FLRV, Rocha, DCC, Lima, JGV, Silva, FNA \& Assis, FGV 2008, 'Tolerância do Tifton 85 (Cynodon spp.) e da Brachiaria brizantha ao Glyphosate', Planta Daninha, vol. 26, no. 2, pp. 353-360.

Silva, MA, Aragão, NC, Barbosa, MA, Jeronimo, EM \& Carlin, SD 2009. 'Efeito hormótico de gliphosate no desenvolvimento inicial de cana-de-açúcar', Bragantia, vol. 68, no.4, pp. 973-978.

Silva, W, Vilela, D, Cobucci, T, Heinemann, AB, Reis, FA, Pereira, AV \& Ferreira, RP 2004, 'Avaliação da eficiência de herbicidas no controle de plantas daninhas em alfafa', Ciência e Agrotecnologia, vol. 28, no. 4, pp. 729-735.

Steinrücken, HC \& Amrhein, N 1980, 'The herbicide glyphosate is a potent inhibitor of 5-enolpyruvyl-shikimic-acid 3-phosphate synthase', Biochemical and Biophysical Research Communications, vol. 94, no. 4, pp. 1207-1212.

Valle, CB, Macedo, MCM, Euclides, VPB, Jank, L \& Resende, RMS 2010, 'Gênero Brachiaria', in: DM Fonseca \& JA Martuscello (eds.), Plantas Forrageiras, Universidade Federal de Viçosa, Viçosa, Minas Gerais, Brasil, pp. 30-77.

Weed Science Society of America (WSSA) 1994, Herbicide handbook. Champaign, Illionois, 352p. 